\title{
IMPORTÂNCIA DA COMUNICAÇÃO INTERNA NA ALIANÇA FRANCESA DE CURITIBA
}

Etienne Gomes de Sennes Pinto ${ }^{1}$

João Augusto Moliani²

\section{RESUMO}

Este artigo tem por objetivo analisar os ambientes organizacionais das sedes da Aliança Francesa de Curitiba e, baseado na Comunicação Empresarial, as ações de Comunicação Interna já utilizadas, levantando a sua importância e benefícios para a organização. Para entender este processo, foi estudado como a cultura organizacional pode influenciar na comunicação interna. Foram levantadas também propostas através da análise realizada. $\mathrm{O}$ artigo está estruturado da seguinte forma: primeiramente teremos a conceituação de cultura organizacional, o funcionamento da comunicação nas organizações e da comunicação interna e, na sequência, a descrição geral da organização, a descrição das ações de comunicação interna da Aliança Francesa de Curitiba e as proposições.

Palavras-chave: Comunicação interna; Cultura organizacional; Aliança Francesa de Curitiba.

\begin{abstract}
The aim of this paper is to analyze the organizational environments at Alliance Française at Curitiba. By using theories of business communication, we seek to measure the communication actions developed in this organization. In order to understand this process, we have studied how the organizational culture can affect the internal communication. As we finished our study, we put forward some solutions to solve the problems faced by the organization. This paper has been structured according to the following: we stress the concept of organizational culture, the role of organization communication, actions of internal communication, and, the last, we describe how these tools are used at Aliança Francesa de Curitiba.
\end{abstract}

Palavras-chave: Internal communication; organizational culture; Alliance Française at Curitiba.

\footnotetext{
${ }^{1}$ Especialista em Comunicação Empresarial e Institucional pela Universidade Tecnológica Federal do Paraná (UTFPR).

2 Jornalista, mestre em Letras (UFPR), professor assistente I da Universidade Tecnológica Federal do Paraná.
} 


\section{CULTURA ORGANIZACIONAL}

A palavra cultura vem da ideia simbólica de cultivo da terra, referindo-se basicamente ao desenvolvimento refletido nos sistemas sociais de conhecimento, ideologia, valores, leis e rituais quotidianos. Isto quer dizer que diferentes sociedades possuem níveis, padrões de desenvolvimento e estilos de vida diferentes.

Mas, foi a partir dos anos 70 que surgiu a perspectiva da cultura como organizacional. Ela expressa valores, crenças e ideais compartilhados por todos os membros da organização. A organização é produtora de sua cultura. Elas são homogêneas e construídas a partir de processos de gestão. Já a cultura nas organizações trata a organização como produtor de um ambiente macrossocial, composto por sociedade, classes, etc.

Sendo assim, cada organização possui suas particularidades, ou seja, um sistema complexo e humano e com características próprias. Com isso podemos dizer que cada instituição tem sua própria cultura e seu próprio sistema de valores.

A cultura organizacional, segundo Chiavenato (1999), "significa o modo de vida, o sistema de crenças, expectativas e valores, a forma de interação e relacionamento típicos de determinada organização".

Srour (1998) complementa que "A cultura organizacional exprime então, a identidade da organização. É construída ao longo do tempo e serve de chave para distinguir diferentes coletividades". Os dois autores partem do mesmo princípio; que a cultura é construída a partir do seu nascimento e vai adquirindo particularidades com o tempo. Ela não parte de uma herança biológica ou genética, mas sim é o resultado de um aprendizado diário socialmente condicionado.

Uma cultura organizacional consiste basicamente em valores e crenças, não é expresso por palavras, é caracterizada pelo tipo de pessoas que se contrata e pelo comportamento de quem trabalha e em qual situação é recompensada. A empresa pode ser formal ou informal, pode ser rígida ou mais tolerante e ter possibilidade de sucesso. Haverá conflitos quando surgirem problemas relacionados a valores mais amplos da vida, como respeito pelos funcionários, tratamentos justo para com o público ou falta de ética. Se uma organização conseguir atrelar um sistema de valores certos, a credibilidade surge 
naturalmente contribuindo para uma boa visibilidade, bom desempenho e o lucro (GALLAGHER, 2003).

A cultura organizacional se forma a partir do momento em que as pessoas se relacionam. Portanto, a cultura é construída e reproduzida pelas pessoas, pois são elas que criam significados e entendimentos (MARCHIORI, 2006).

Neste sentido, Marchiori investiga ainda as características culturais através do universo em que os integrantes da organização estão inseridos. Esta análise consiste em identificar o teor e o processo de socialização, crenças, valores e convicções dos seus criadores, pesquisar a história, arrecadar críticas e explorar junto aos membros da organização as conclusões básicas e a interação que ocorre internamente.

Por esse motivo é que Chiavenato (1993) afirma ser a cultura organizacional condicionante e determinante das normas de comportamento das pessoas dentro de cada empresa. "É a maneira de ser de cada empresa e de seus participantes".

Fleury e Fischer (1996) ressaltam que, para a cultura ser criada e mantida, concepções como normas e valores devem ser de conhecimento dos membros através de ações que demonstrem sua existência na organização. Os ritos, rituais, gestos e entre outros, são as expressões da cultura organizacional.

A cultura de uma organização não é tão fácil de identificar, mas é um fator de grande importância. Podemos analisar esse contexto através da execução do trabalho diário, de críticas recebidas ou desenvolver os pressupostos básicos da organização. Para a identificação desse pressuposto, é preciso o levantamento de dados sobre a relação com a natureza, ou seja, se está relacionado com o meio ambiente em forma de dominação, harmonia ou submissão; a natureza da realidade é real; diferenciar os fatos reais, descobrindo o que aconteceu anteriormente; como é distribuído o poder, a competição e a cooperação, tradição, autoridade ou carisma (SHEIN, 1985).

Seguindo este raciocínio, Gallagher (2003) explica que os valores são repassados de chefe para funcionário e entre os funcionários e, segundo Marchiori (2006), a função de construção da cultura dentro da organização é do gestor. Mesmo sendo uma pequena empresa ela terá sua própria cultura. É possível conseguir valorizar e criar pontos fortes e modificar os fracos, se manter o foco da empresa na cultura.

As grandes organizações são compostas de culturas dominantes e diversas subculturas, ou seja, uma cultura que expressa valores essenciais divididos pelos 
membros e pelas pequenas culturas, que são definidas por departamentos. Se não houvesse essa separação na cultura organizacional, o valor dela como variável independente não seria significante, ou seja, a cultura seria uniformizada sem análise de cada problema que a organização possui. Através dessa pesquisa é possível orientar e modelar o comportamento organizacional (ROBBINS, 2002).

Por outro lado, Torquato (2004) levanta a questão relacionada ao comodismo de muitos executivos, que temem conhecer a realidade das culturas organizacionais. Estes pensam que pesquisando a verdade, através de atitudes superficiais e de rotina, podem enganar a todos e contornar conflitos internos. Para não serem vistos como vilões, tendem a evitar questões polêmicas para não serem mal entendidos. Dessa forma, suas ações são falhas, pois, ao invés de administrar problemas, as abafam para não se incomodarem.

Tendo em vista essa questão, podemos dizer que em uma organização bemsucedida a análise de sua cultura é apenas a primeira tarefa a ser desempenhada. A equipe formada deve trabalhar em busca dos objetivos organizacionais, juntamente com o corpo diretivo. Para isso, a integração entre os componentes deve ser liderada por uma pessoa que tenha visão dos objetivos a serem alcançados.

\section{COMUNICAÇÃO NAS ORGANIZAÇÕES}

Nas organizações bem-sucedidas, a comunicação é uma das maiores prioridades. A maioria das ações do dia a dia são atos comunicativos, sendo eles verbais ou não. Define-se a comunicação então como um intercâmbio de informações e transmissão de significado, sendo a própria essência de um sistema social ou uma organização.

Para uma organização tornar-se bem-sucedida é necessário investir na comunicação. Tempo e dinheiro investidos na comunicação com os funcionários fazem diferença e tornam-se o caminho para a inovação e uma vida mais simples (LACOMBE, 2005).

A comunicação constitui também um dos elementos essenciais no processo de criação, transmissão e cristalização da essência da organização. Para melhor 
entendimento dos meios de comunicação, é preciso identificar tanto os meios formais orais e escritos como os meios informais. Identificando estes meios é possível facilitar a integração entre grupos, categorias e áreas da organização.

A comunicação informal por ser mais tática e ágil, pois ela pode transformar a estrutura formal e representam um importante papel na organização. Elas surgem nas relações sociais entre as pessoas. Não é solicitada nem contratada, mas reflete na liderança de alguns indivíduos da organização.

Nas novas organizações, a introdução de diferentes canais de comunicação entre empresa e funcionário são cada vez mais aplicados e aprimorados, pois a transparência e a integração de quem trabalha na organização acarreta o bom relacionamento entre as partes (FLEURY E FISCHER, 1998).

Neste sentido, Lacombe (2005) enfatiza que os meios de comunicação na empresa, como o contato direto, ainda é um instrumento que se sobressai entre os outros. A linguagem corporal proporciona informações com que os meios não têm condições de lidar. Este contato é adquirido através de palestras, encontros sociais, conversas formais e informais, etc. Já os documentos escritos possibilitam uma recuperação completa e precisa da informação, exemplos deles são os relatório, atas de reunião, cartas, etc. Outro meio influente é o eletrônico, sua utilização e importância vem crescendo em decorrência de informações enviadas via intranet nas empresas e possuem baixo custo.

O autor já citado ainda resume as principais características de uma boa comunicação:

- $\quad$ Objetividade: conhecer o público-alvo e saber ouvir;

- $\quad$ Linguagem adequada: clareza, voz ativa, correção e coesão;

- $\quad$ Fidelidade ao pensamento original: tradução do pensamento e eliminação da filtragem;

Nos documentos escritos devem ser tomadas algumas precauções:

- Usar termos claros e simples;

- $\quad$ Evitar erros gramaticais;

- $\quad$ Ser conciso;

- $\quad$ Organização de itens; 
- Usar os verbos na voz ativa;

- $\quad$ Colocar-se na posição do leitor;

- Revisar o texto escrito e submeter à análise de outras pessoas.

A análise dos procedimentos básicos da comunicação sustenta o estudo de como realizar a comunicação dentro das organizações.

A comunicação interna ou é analisada inicialmente como um conjunto de ações pertinentes ao público interno e tem a função de integrar e conscientizar funcionários e a chefia da importância do cliente nos processos internos da estrutura organizacional, fazendo com que o relacionamento, o atendimento, a qualidade dos produtos e serviços seja de qualificada (ERBANO, 2005).

\subsection{COMUNICAÇÃO INTERNA}

Atualmente, a comunicação interna constitui ferramenta de grande importância nas organizações. Kunsch (2003) explica que a comunicação interna não substitui o funcionamento da comunicação no sistema organizacional, através de seus fluxos, níveis e redes informais e formais. Trata-se de um setor planejado, que trabalha com objetivos definidos que visa viabilizar a interação entre funcionários e a organização, utilizando ferramentas de comunicação institucional e mercadológica, como o endomarketing. Ela acontece paralelamente com a circulação normal da comunicação que perpassa todos os setores de organização, para o bom funcionamento da organização.

Na mesma linha, Torquato (2004) explica que os profissionais dão ênfase à rede formal, oficial, que comunica os funcionários. A rede informal, muitas vezes, é deixada de lado, ou por não ser conhecida, ou por não ser trabalhada de forma mais visível. É nesta rede que são encontrados todos os sentimentos do público interno em relação à organização. Utilizar-se dela possibilita o trabalho de argumentação e convencimento, situando todos os grupos formando equipes que trabalhem por um objetivo em comum. Em ambas é possível realizar trabalhos eficientes à organização. Através de quadros de avisos, murais, espaços abertos é possível trabalhar no planejamento, buscando ideias novas, simples e funcionais. 
Marchiori (2006) diz ainda que a comunicação interna realiza a troca de informações via comunicação, contribuindo para a construção do conhecimento, o qual é transmitido nas atitudes do indivíduo. É fundamentalmente um processo que engloba a comunicação administrativa, fluxos, barreiras, veículos, redes formais e informais. Este processo oportuniza a interação e a credibilidade, fortalecendo a identidade da organização.

Sendo assim, o ambiente organizacional não deve ser visto como um mercado, mas sim um organismo que necessita trabalhar em conjunto para que todos compreendam o seu papel na empresa (KUNSCH, 2003).

A comunicação interna só irá funcionar se for participativa e coerente entre discurso e a prática diária das organizações. Grandes programas de comunicação não adiantarão de nada se o funcionário não for respeitado, ouvido e ser considerado o público principal.

As mudanças decorrentes no mundo atingem direta e indiretamente as organizações, provocando novas atitudes e reações. O funcionário não é mais o último a saber da vida da empresa, existem inúmeras fontes para tal. A abertura democrática do país proporcionou uma mudança comportamental nos empregados, estes estão menos acomodados, tornando-se mais ativos na organização.

Podemos considerar a comunicação interna como uma área estratégica, na qual deve ser trabalhada em conjunto a cúpula diretiva da empresa, responsável por implantações e colaboradores internos envolvidos.

O grande problema é a compatibilizar os interesses da empresa e o trabalho. O atual cenário brasileiro não cultiva valores comunitários e sim vantagens econômicas sem considerar o todo. Para que a comunicação interna seja implantada, o todo deve ser levado em conta, além de desenvolver a confiança entre emissores e receptores. A motivação faz com que o funcionário sinta-se parte integrante do processo organizacional e também se sinta valorizado.

Em síntese, a valorização de funcionários não depende, portanto, apenas de bons salários. As organizações atualmente não percebem nem aproveitam o capital humano, descartando pessoas que poderiam contribuir no crescimento da empresa. Por consequência, desestimulam a dedicação às atividades, limitando-se ao trivial. 
O público interno é o principal porta-voz da organização perante seus familiares e convívio pessoal, de uma forma positiva como negativa. Tudo depende do seu relacionamento na empresa e com o produto e serviço oferecido. É através da comunicação interna que permitirá aos colaboradores serem bem informados, mediando conflitos e prevenindo problemas futuros (KUNSCH, 2003).

Uma das ações de comunicação interna é a formação de multiplicadores de informações: escolher funcionários que possam liderar processos e ajudar no planejamento da comunicação interna. Com isso, o funcionário escolhido para liderar seu setor, sente-se valorizado, pois representa a organização para os outros funcionários e vice-versa (SANTOS, 2005).

\subsection{LIDERANÇA}

O sucesso de uma organização depende principalmente de uma equipe que saiba realizar as tarefas de forma integrada e eficaz. Para que os objetivos sejam atingidos, é preciso liderança, que faz parte do trabalho em equipe, sendo assim necessária em todas as atividades e em qualquer tipo de organização humana.

O conceito de liderança, segundo Robbins (2002. pg. 304), explica que:

Liderança é a capacidade de influenciar um grupo em direção ao alcance de objetivos. A origem dessa influência pode ser formar, como a conferida por um alto cargo na organização. Como essas posições subentendem certo grau de autoridade, uma pessoa pode assumir um papel de liderança apenas em função do cargo em que ocupa. Nem todos os líderes são administradores e nem todos os administradores são líderes.

A esse respeito, Chiavenato (1997) também ressalta que um bom gerente ou dirigente não precisa ser necessariamente um bom líder e vice e versa. Estes devem estar presentes em todos os níveis da organização para solucionar conflitos existentes e realizar um trabalho integrado de equipe. Neste sentido, lidando com pessoas principalmente, torna-se o principal foco da liderança.

Em sentidos técnicos, Chiavenato (1997, pg.147), já citado, conceitua liderança como: 
Um fenômeno tipicamente social que ocorre exclusivamente em grupos sociais. Podemos defini-la com uma influência interpessoal exercida numa dada situação e dirigida através do processo de comunicação humana para a consecução de um ou mais objetivos específicos.

Tais observações mostram que a liderança é caracterizada por uma influência entre pessoas, ou seja, uma pessoa influencia outra por relacionamentos existentes entre as partes. Tem por objetivo modificar ou provocar o comportamento de outra pessoa intencionalmente. Existem vários graus de influência, tais como:

- Coação: coagir mediante pressão;

- Persuasão: convencer uma pessoa por meio de conselhos e argumentos ou induções;

- Sugestão: apresentar plano ou ideia à uma pessoa ou grupo;

- Emulação: imitação com vigor para se igualar ou chegar quase ao mesmo ponto que alguém.

Temos ainda a liderança que ocorre em algumas situações, por exemplo, em decorrência da distribuição de autoridade para tomada de decisões. E, por fim, temos a liderança através do processo da comunicação humana, através da indução de cumprir com as obrigações demonstrando as percepções do líder para atingir objetivos organizacionais.

Para que o líder tenha um bom aproveitamento de sua atividade, o gerente deve saber administrar "alguns aspectos de motivação, comunicação, relações interpessoais, trabalho em equipes e dinâmica de grupos" (CHIAVENATO, 1997).

Robbins (2002) desenvolveu cinco teorias sobre liderança, abrangendo desde a diferença entre os líderes até a ênfase no simbolismo e no emocional:

1. Teorias sobre Liderança: A diferença entre alguns líderes e porque alguns são melhores que outros; Esta teoria procura explicar o comportamento em grupo através da liderança, pois é o líder que direciona os objetivos e realiza um plano estratégico para alcançá-lo;

2. Teoria dos Traços: Diferenciação de líderes e não-líderes por traços físicos, intelectuais ou de personalidade; Não é tão eficiente quanto às outras, pois analisa 
somente algumas características pessoais que não se modificam com a situação apresentada;

3. Teorias Comportamentais: Comportamentos específicos que distinguem os líderes dos liderados;

4. Teorias das Contingências: O grau de desempenho do grupo em relação à adequação do estilo de líder e às diferentes situações; Essa teoria pode ser considerada eficiente, pois trabalha com situações e um líder deve saber administrar diferentes momentos da organização;

5. Teorias Neocarismáticas: Enfatizam o simbolismo e o emocional exercidos por determinados líderes. Mas atualmente a teoria carismática vem ganhando seu espaço. O carisma dos líderes pode ser mais eficiente para administração de conflitos do que apenas saber controlá-los sem ter esta característica.

Para que a liderança tenha eficiência é necessário desenvolver a motivação, através da confiança, ou seja, amizade, apoio e estabilidade. Para isso, alguns fatores são essenciais neste processo:

- Influência do gerente: percepção, pela equipe, de que o líder deseja ajudála, para atingir suas metas, educando-a para novas ações e elogiando-a em bons resultados;

- Bom ambiente de trabalho: lugares arrumados, limpos, trabalhos interessantes, justiça, amizade e cooperação;

- Trabalho em grupo; formar uma equipe para realizar um trabalho colaborativo proporciona um trabalho mais agradável e eficiente; Reconhecimento: Alegria em atingir as metas, elogiando-os;

- Crescimento e aprendizado constantes.

\section{A ALIANÇA FRANCESA DE CURITIBA}

A Aliança Francesa foi inaugurada em 21 de julho de 1883 por um comitê constituído por nomes como: Paul Chambon, Ferdinand de Lesseps, Louis Pasteur, 
Ernest Renan, Jules Verne e Armand Colin. Atualmente, a Associação tem mais de 1000 estabelecimentos, instalados em 130 países.

No Brasil, ela está presente há 125 anos. A rede conta com 40 associações e 9 centros correspondentes, em praticamente todos os estados brasileiros. Por ser uma associação, ela é uma instituição sem fins lucrativos, que tem por objetivo a difusão da cultura e da língua francesa pelo mundo. Todas as Alianças Francesas são independentes (administrativa e juridicamente), tendo apenas os exames, método e atividades culturais administradas pela Delegação Geral no Brasil, situada do Rio de Janeiro.

A Associação de Cultura Franco-Brasileira, a Aliança Francesa de Curitiba, foi fundada em 31 de janeiro de 1945 pela fusão do "Centro Literário Franco Brasileiro" com a "Alliance Française" - seccional de Curitiba, que sucedeu ao "Centro Francês do Paraná" constituído em 18 de agosto de 1932. A ACFBC é uma Associação sem fins lucrativos, entidade jurídica e financeiramente autônoma, de duração indeterminada, com sede e foro na cidade de Curitiba, Capital do Estado do Paraná, na Rua Prudente de Moraes, $n^{\circ} 1101$; reconhecida como de utilidade pública pela Lei Estadual n ${ }^{\circ} 5.257$, de 13 de janeiro de 1966 e pela Lei Municipal nº 2.868, de 21 de setembro de 1966, regendose por este Estatuto Social e pela legislação brasileira.

Hoje, a Aliança Francesa conta com as sedes Prudente de Moraes e Fábrika. Esta sede é locada e está localizada na Rua Fernando Amaro, 154, Alto da XV, desde 2011. Outros estabelecimentos foram abertos em outros endereços desde 1945, mas foram vendidos para diminuir gastos, pois não havia necessidade na época para mais de uma escola.

A Aliança Francesa sempre foi considerada como centro de cultura francobrasileira em Curitiba, além de ser referência no ensino da língua francesa. A associação conta com uma mediateca completa com cerca de 7.000 documentos entre livros, histórias em Quadrinhos, DVDs, Vídeos, CDs, assinaturas de periódicos e revistas, gramáticas, dicionários e livros infantis, aberto ao público interno e externo.

Em relação à associação, ela é constituída por um número ilimitado de associados, que são incorporados junto à organização, de acordo com os preceitos legais e estatutários. A ACFBC mantém as seguintes categorias de associados: 
a) Associados Temporários: pessoas físicas admitidas no quadro associativo em caráter temporário, sem direito a voto, cujo objetivo é apenas o de frequentar a mediateca da Aliança Francesa de Curitiba, sem acesso à intranet.

b) Associados Efetivos: pessoas físicas ou jurídicas admitidas sem restrições de direitos. Este sócios podem participar de Assembleias Gerais, votar e ser votado, desde que estejam em dia com o pagamento anual. Para se tornar sócio efetivo o interessado deve preencher um formulário fornecido pela Secretaria da AF ou impresso diretamente do site e em seguida será apreciado pelo Conselho Diretor.

c) Associados Honorários: Esta categoria de sócio é definida pela associação onde são homenageados aqueles que contribuíram pessoal e decididamente para a realização dos objetivos da ACFBC.

Os Sócios Efetivos e Honorários têm acesso à intranet da Aliança Francesa, para utilização da mediateca para consultas e empréstimos de materiais, recebimento da revista "La Gazette" - publicação bilíngue francês/português editada pela Aliança Francesa de Curitiba, assim como acesso prioritário às atividades culturais.

\subsection{DIFERENÇAS ENTRE AS SEDES}

A Aliança Francesa é uma das instituições de ensino em língua estrangeira com maior referência em qualidade e formação de seus professores. A sua tradição perante a sociedade é bastante reconhecida. Como resultado, na inauguração da Fábrika, o primeiro semestre obteve aproximadamente 100 alunos inscritos. Atualmente, as duas sedes matricularam no último semestre de 2011 um total de 801 alunos novos e rematrículas (638 da Prudente de Moraes e 163 da Fábrika).

As sedes têm 49 funcionários, sendo que o corpo docente é composto de 28 professores (22 da Prudente de Moraes e 6 da Fábrika); 21 funcionários do corpo administrativo (17 da Prudente de Moraes e 4 da Fábrika).

O corpo docente é liderado por 2 coordenadores, que são responsáveis pela elaboração de cursos, propostas de projetos para os alunos e demais assuntos acadêmicos das duas sedes (usar sedes sempre em minúsculo). Na parte administrativa, temos 2 gerentes, um responsável pelo administrativo e financeiro e outro pelo marketing. $\mathrm{O}$ diretor, vindo geralmente da França, é substituído a cada 4 anos, não faz parte do quadro 
de funcionários, pois recebe seus benefícios do Governo na França. Este é responsável por guiar as atividades culturais e pedagógicas que devem ser exercidas em todas as Alianças Francesas. Todos os coordenadores, gerentes e diretor revezam duas atividades nas duas sedes.

Em relação ao estatuto, a associação possui conselhos eleitos bienalmente: o Fiscal composto por 5 membros efetivos e 2 suplentes e o Diretor, composto por 1 Presidente de Honra, 1 Presidente, 1 Vice-Presidente, 1 Secretário, 1 Tesoureira e 2 Vogais. Os membros dos Conselhos não são remunerados.

Apesar de não existir um organograma pré-estabelecido na organização, podemos organizar o quadro de funcionários e membros da associação da seguinte forma:

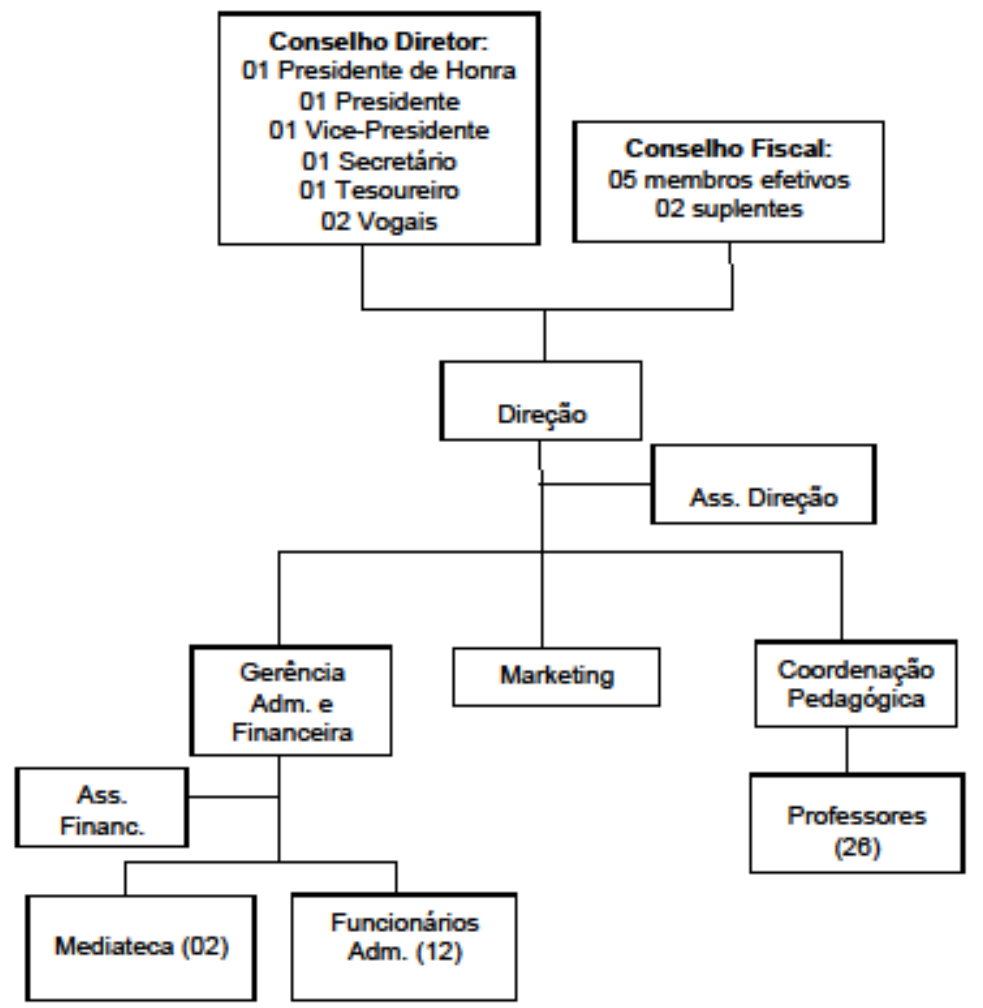

As sedes possuem algumas características individuais que as diferenciam. $\mathrm{Na}$ entrada da Prudente de Moraes, temos a secretaria do curso que fornece informações para o público externo, alunos e funcionários. Ao lado, há um café (Café Babette) que também 
é aberto ao público externo. Os funcionários que trabalham no atendimento direto utilizam uniformes preto e branco, todos formais.

A Fábrika está localizada dentro de um complexo histórico e segue a identidade visual do estabelecimento. Este possui espaços de socialização e divide este espaço com a escola de Alemão Goethe, de espanhol, Cervantes, academia de dança e de musculação. Além disso, no mesmo prédio da Aliança Francesa estão instalados o Consulado da França e a Câmara de Comércio França-Brasil. Este é um fator muito interessante para a Aliança Francesa, pois estes estabelecimentos trazem franceses, eventos e parcerias.

A sede da Prudente de Moraes difere da Fábrika por três motivos: O número de alunos, tempo de existência e o fato de serem diferentes em sua cultura. Os professores por estarem a mais tempo na instituição têm dificuldades nos processos de mudanças e integração, diferentemente do corpo docente mais novo, alocado na sede da Fábrika. Por tratar-se de estabelecimentos de pequeno porte, têm dificuldades em estabelecer um programa de carreira e também um programa de estímulo e integração de funcionários.

\subsection{PÚBLICOS}

Os públicos da Aliança Francesa foram analisados e identificados de acordo com a proposta de Simões (1995), que os classifica utilizando o critério do tipo de poder para dividi-los em quatro tipos: decisão consulta, comportamento e opinião.

Decisão: permite a permanência e suspensão de atividades da organização, sendo a Diretoria e os Conselhos da Sede;

Consulta: os sindicatos das escolas particulares e a associação dos professores de francês.

Comportamento: Neste temos o público interno, os funcionários da Aliança Francesa e seus gerentes administrativos e corpo docente. Os clientes da escola também entram nesta categoria, pois permitem a permanência da organização no mercado. Neste público possui de crianças à adultos, dos 6 a 80 anos, sendo na sua maioria mulheres. Os interesses são variados, mas os principais são em relação à imigração para o Quebec, estudos na França e funcionários de empresas francesas instaladas em Curitiba e Região Metropolitana. 
Opinião: compreendem os jornalistas e políticos envolvidos com escola, sendo um dos pontos fortes da Aliança Francesa, por se tratar de uma associação tradicional na sociedade curitibana. A Aliança Francesa possui um bom relacionamento com a mídia local e grande interesse em parcerias culturais.

\section{A COMUNICAÇÃO NA ALIANÇA FRANCESA}

O mix utilizado para a divulgação da escola utiliza-se da publicidade com criações de campanhas em época de matrículas veiculadas em mobiliários urbanos, banca de revistas, outdoors, chamadas em rádios, mídias sociais, twitter (ANEXO A), facebook (ANEXO B) e o site oficial (ANEXO C).

Também são feitos releases elaborados por um assessor de imprensa contratado, que encaminha para os principais meios de comunicação regionais. Além disso, existe uma publicação bimestral chamada "La Gazette"(ANEXO D) distribuída aos sócios, alunos, parceiros e ao público que visita a escola, com o objetivo de divulgar a programação cultural, a cultura francesa, curiosidades, artigos literários franceses, informações culturais e etc. Tiragem de 3000 exemplares, distribuída gratuitamente.

A Aliança Francesa realiza também parcerias com os principais eventos culturais de Curitiba, como o Festival de Teatro, Festival Varilux de Cinema Francês e com empresas como a Câmara de Comércio França-Brasil e o Consulado da França. As parcerias funcionam através de sorteio de ingressos para os festivais em troca da divulgação da Aliança Francesa no evento e vice-versa. Com as empresas, a parceria acontece na divulgação dos cursos e muitas vezes a escola disponibiliza o espaço para eventos.

\subsection{A COMUNICAÇÃO INTERNA NA ALIANÇA FRANCESA DE CURITIBA}

A Aliança Francesa de Curitiba trabalha com algumas ações de comunicação interna na empresa.

\subsubsection{Reuniões Administrativas}


Descrição: existe um calendário para as reuniões administrativas e de setores, para que os funcionários possam se programar, caso não seja no horário de trabalho. As reuniões são sempre à tarde, nas sextas-feiras.

Objetivo: nestas reuniões são tratados assuntos de interesse comum do corpo administrativo e aberto à todos para levantar pautas. Também é um espaço para que todos os funcionários das sedes possam trocar idéias e informações.

Problemas: a grande maioria não acha que as reuniões são produtivas e que resolvam os problemas existentes na organização. As reuniões atrapalham no atendimento da Secretaria, mesmo sendo em um dia de pouco ou nenhum movimento.

\subsubsection{Intranet}

Descrição: a escola possui dois sistemas utilizados para intranet. No momento o mais utilizado é o de função administrativa (Matheus Soluções).Este sistema é utilizado em diversas escolas para gerenciar toda a vida acadêmica do aluno, realizando matrículas, recebimentos de pagamentos, registros de históricos, além de registrar toda a parte administrativa e financeira da escola. Existe também uma função de intranet na qual permite comunicação entre funcionários, através de chat e mensagens.

O outro sistema disponível, Bureau Virtuel foi lançado em 2010 para todas as Alianças Francesas do Brasil e também pode ser utilizado como intranet, mas é utilizado apenas pela Secretaria. Ele tem a função de compartilhar arquivos entre grupos. Também pode ser usado para divulgação de atividades específicas para cada grupo.

Objetivo: informar os funcionários sobre os acontecimentos da organização e também notícias sobre a escola.

Problemas: Dificilmente os funcionários utilizam a intranet para se informar. A informação geralmente é passada por e-mail, telefone ou através de conversas informais. A intranet é usada para baixar documentos ou para se informar, quando é avisado aos funcionários que os arquivos e notícias estão disponíveis nesses meios.

\subsubsection{E-mails pessoais}


Descrição: cada funcionário tem seu próprio e-mail e é através dele que a gerência administrativa encaminha a maioria dos comunicados, tanto gerais, por setor e individuais.

Objetivo: informar funcionários mais rapidamente.

Problemas: a leitura de e-mails ainda não é uma rotina usual de todos. Os funcionários que não trabalham com o computador diretamente, utilizam o computador poucas vezes na semana.

\subsubsection{Quadro de avisos}

Descrição: este quadro existe apenas para o corpo docente e na cozinha da Sede, geralmente usado pelo setor de serviços gerais. Na Filial não é utilizado. As secretarias também não utilizam este instrumento.

Objetivo: informar funcionários nas mudanças de turno.

Problemas: o quadro de avisos é necessário, pois existem trocas de turnos, na qual os funcionários muitas vezes não se comunicam. Não há um espaço físico adequado para a implantação deste instrumento.

\subsubsection{Af Nouvelles - informativo interno}

Descrição: informativo simples, formato A4, dobrado ao meio, distribuído em reuniões ou antes delas para todos os colaboradores, com informações sobre eventos, cursos, exames aplicados na escola referente ao mês, aniversários, horários, etc.

Objetivo: unificar as informações de uma maneira simples e direta o que acontecerá em cada mês na escola.

Problemas: aqueles que costumam ler e-mails, não tem o hábito de guardálos para futuras consultas.

\subsubsection{Confraternizações}

Descrição: é realizado todo final de ano, uma pequena comemoração com todos os funcionários na Sede, na qual recebem lembranças da escola 
Objetivo: motivar a todos que participam e reforçar os laços que unem as pessoas por objetivos em comum.

Problemas: o horário das confraternizações deve ser avisado com antecedência para o público interno e externo.

Apesar do que se faz, é possível aprimorar a comunicação interna para que a Aliança Francesa de Curitiba alcance seus objetivos. Sendo uma das partes fundamentais da comunicação empresarial, a comunicação interna terá a função de orientar e transmitir para o seu público interno informações e política empresarial. E, através dela, é possível treinar, sensibilizar, motivar e cativar seus funcionários, tudo isto através do diálogo constante com seus colaboradores, tornando-se um processo colaborativo. (KUNSCH, 2003)

\subsection{SUGESTÕES}

Através das observações realizadas sugere-se que sejam realizadas pesquisas de satisfação dos colaboradores e um diagnóstico da comunicação interna e posteriormente elaborado um plano estratégico de comunicação interna. Com isso, será possível encontrar as falhas de comunicação entre Sede e Filial e evitar futuros problemas de informações desencontradas.

Outra proposta a ser considerada é uma avaliação 360 para o aperfeiçoamento e desenvolvimento dos funcionários através de questionário para melhorar processos empresariais e a qualidade de vida no trabalho. Com isso, constata-se a importância de um Manual Interno para ser possível ter alguma referência sobre o conhecimento do funcionário em relação à empresa e analisar suas funções.

Um programa de treinamento e de integração com a empresa é necessário, pois muitas informações podem ser passadas ao novo funcionário antes de iniciar seu trabalho na empresa. Líderes poderão ser muito importantes neste processo, pois são eles quem poderão ajudar e integrar os novos funcionários, além de ter conhecimento do setor na qual estão inseridos.

Outro fator a ser considerado na Aliança Francesa seria um Plano de Incentivo aos funcionários necessita ser repensado, como por exemplo, uma administração de cargos e salários por tempo de serviço ou pelas atividades desenvolvidas dentro e fora da 
empresa. A bolsa de estudos para cursar o idioma Francês deveria ser um estímulo ao crescimento dentro da empresa e não apenas um benefício ou obrigação.

\section{CONSIDERAÇÕES FINAIS}

O presente artigo demonstrou, através de participação direta no contexto interno da Aliança Francesa de Curitiba, uma visão geral do ambiente organizacional. Nesta observação, pode-se perceber que existem divergências no organograma gerencial, ou seja, quando Presidência e Diretoria não estabelecem um padrão em suasde decisões, ocorrendo muitas vezes informações truncadas para a organização.

Outro fator constatado internamente foi a insatisfação em relação às funções dentro da empresa. A falta de incentivo e o excesso de rumores atrapalham no dia a dia dos funcionários e dificulta o processo de comunicação, justificando-se assim a importânica da comunicação interna neste processo. A cultura de comunicar-se nesta associação ainda está em desenvolvimento, pois as informações são retidas e não compartilhados com os membros da organização.

As sugestões descritas neste artigo foram apresentadas como um estímulo e para ilustrar a importância de se planejar estrategicamente um fenômeno que muitas vezes não conhecido pelas pessoas. A utilização de canais da comunicação pode tornar este processo mais eficiente e as barreiras superadas, permitindo a intervenção dos funcionários na apresentação de sugestões para a melhoria da comunicação na empresa.

Deve-se compreender que o trabalho de comunicação interna é uma rotina constante, e não deve ser apenas realizado em momentos de crise. Precisa de um planejamento estratégico no qual os membros diretivos tenham conhecimento e atuem em parceria com a comunicação, para que esta possa chegar a todos os membros da organização.

\section{REFERÊNCIAS}

CHIAVENATO, Idalberto. Introdução à Teoria Geral da Administração. 4. Ed. São Paulo: Makron, 1993.

Gerenciando Pessoas. O passo decisivo para a administração participativa. 3.ed. São Paulo: Makron Books,1997. 
Paulo: Atlas, 1999.

Administração de recursos humanos: fundamentos básicos. 4. Ed. São

ERBANO, Luiz Afonso Caprilhone. Gestão e Marketing na era do conhecimento. Curitiba: Champanhat, 2005.

FLEURY, Maria Tereza Leme; FISCHER, Rosa Maria. Cultura e poder nas organizações. 2. Ed. São Paulo: Atlas, 1996.

GALLAGHER, Richard. Os segredos da cultura empresarial. Rio de Janeiro: Campus, 2003.

KUNSCH, Margarida Maria Krohling. Planejamento de Relações Públicas na Comunicação Integrada. São Paulo: Summus, 2003.

MARCHIORI, Marlene. Faces da cultura e da comunicação organizacional. Vol.1. São Caetano do Sul, SP : Difusão Editora, 2006.

ROBBINS, Stephen Paul. Comportamento Organizacional. Título Original: Organization Behaviour.9. ed. São Paulo: Prentice Hall, 2002. 22 Tradução técnica: Reynaldo Marcondes.

SIMÕES, Roberto Porto. Relações Públicas: Função Política. 5. Ed. Ver. Ampl. São Paulo: Summus, 1995.

SCHEIN, Edgard. Cultura organizacional e liderança.Trad. Ailton Bonfim Brandão.

São Paulo: Atlas, 2009.

SROUR, Robert Henry. Poder, cultura e ética nas organizações. 8. Ed. Rio de Janeiro: Campus, 2002.

\section{REFERÊNCIAS ELETRÔNICAS ONLINE}

Gestiopolis: Capital intelectual: a nova vantagem competitiva. Disponível em: $<$ http://www.gestiopolis.com/recursos3/docs/ger/capintel.htm> Acesso: 21/05/2012.

A liderança na comunicação interna. Disponível em: $<$ http://alideranca2009.blogspot.com.br> Acesso: 17/04/2012.

Aliança Francesa de Curitiba. Site Oficial. Disponível em: $<$ http://www.afcuritiba.com.br.> Acesso em 13/04/2011.

TORQUATO, Gaudêncio. A Comunicação interna e os desafios da integração.

Disponível em: <http://www.sinprorp.org.br>. Acesso em: 09/05/2012. 
ANEXOS

ANEXO A - TWITTER

$\leftarrow \rightarrow$ C 凡 $\bigcirc$ twitter.com/\#!/afcuritiba

\begin{tabular}{|l|}
\hline Siga Aliança Francesa \\
\hline Nome Completo \\
\hline E-mail \\
\hline Senha Inscreva.se \\
\hline Tweets \\
\hline Senuindn \\
\hline
\end{tabular}

af Feira de livros na Aliança Francesa: Venha conhecer as ultimas novidades de livros, métodos, gramáticas, áudio e vídeo pic.twitter.com/6YX1vefS

司 Verfoto

- Aliança Francesa @afcuritiba

MS aio, 19 horas na Allanc Francesa pic.twitter.com/u1NIbWiq

\section{ANEXO B - FACEBOOK}

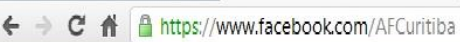

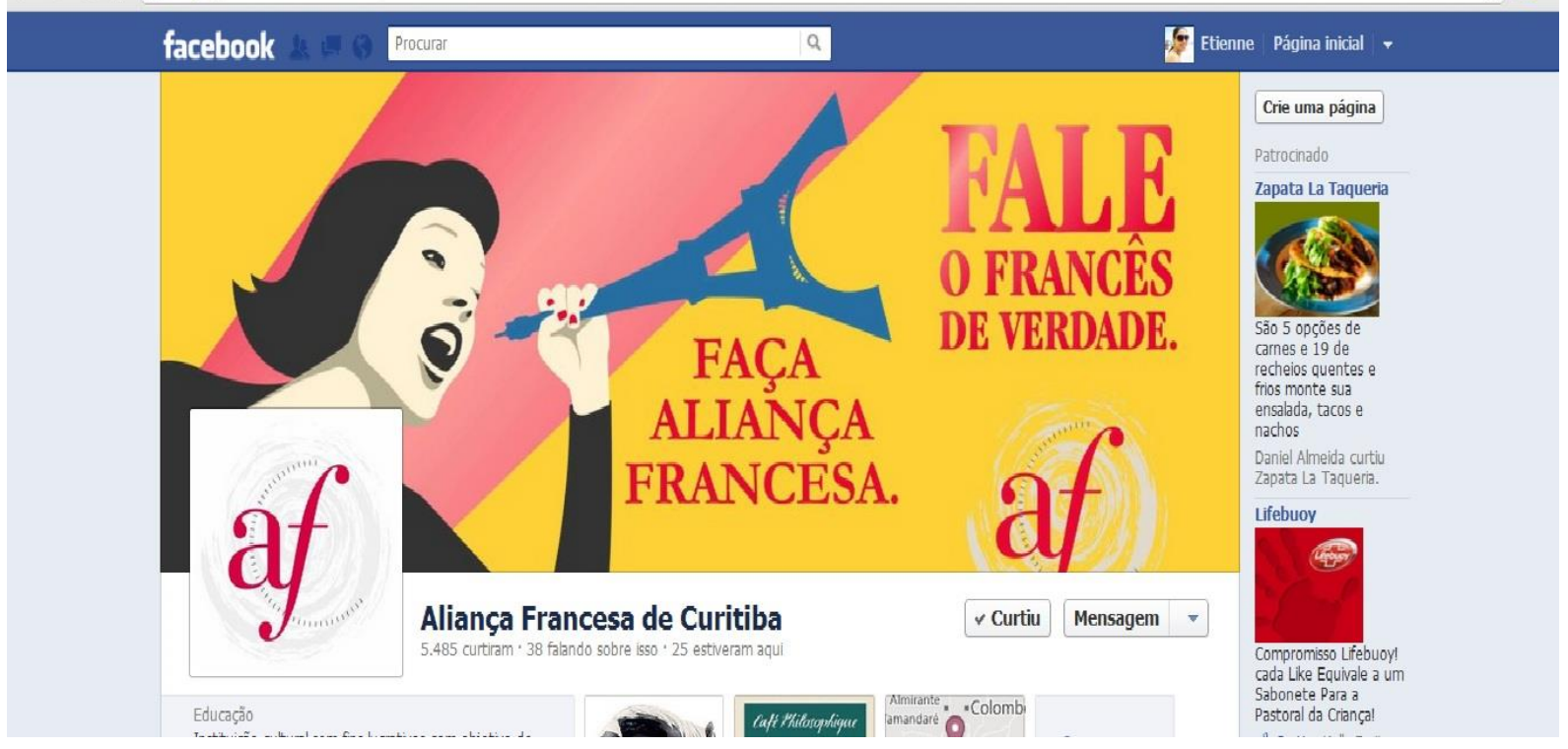

ANEXO C - SITE OFICIAL 

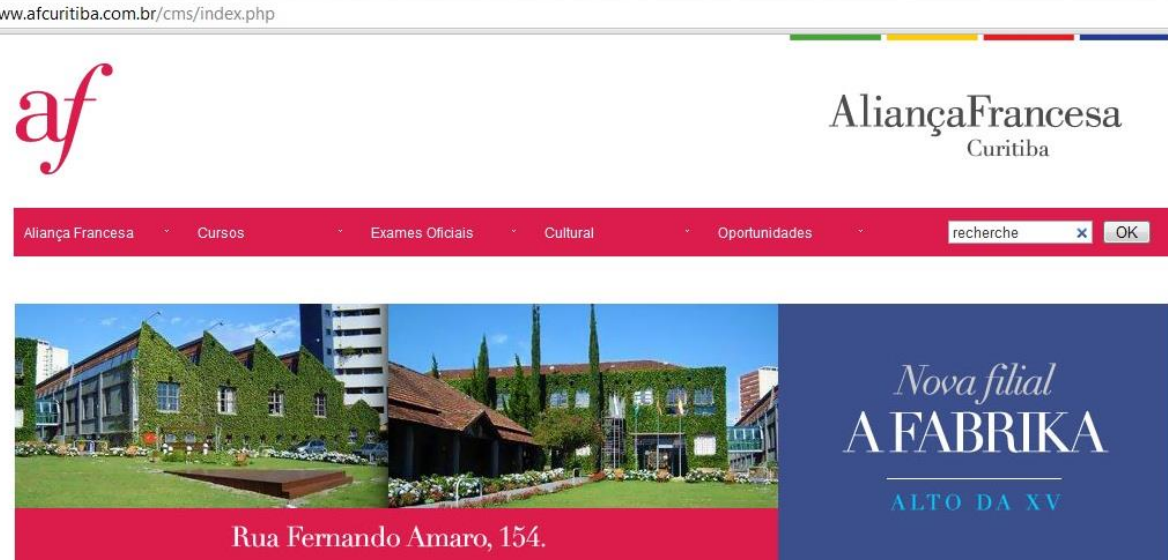

Curso de formação $-2^{\circ}$ quadrimestre 2012 - Matricule-se

Cursos para iniciantes com inicio a partir de 17 de maio.
Ritmo regular ou semi-intensivo

ANEXO D - LA GAZETTE 


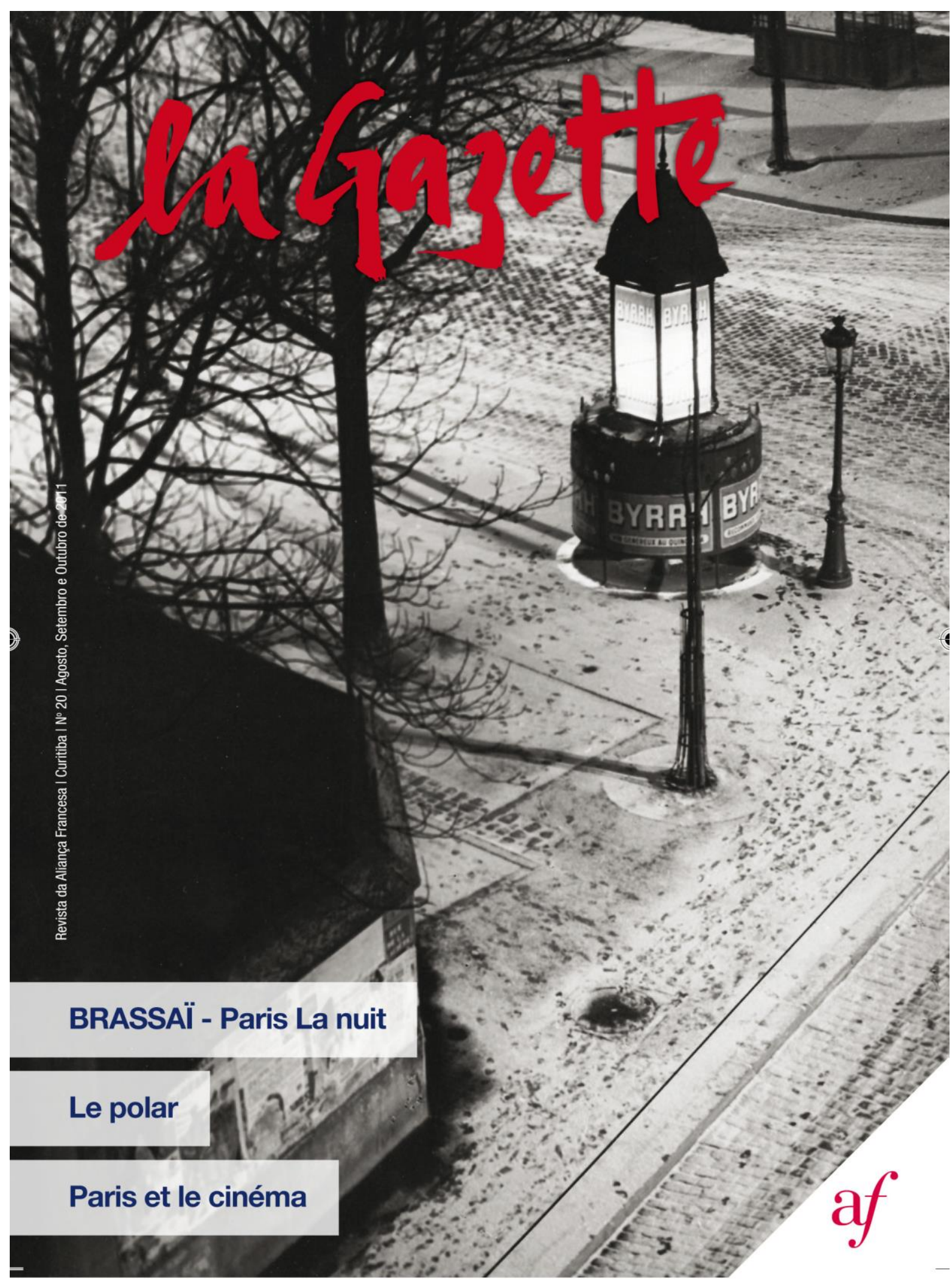

